\title{
Fertility Preservation in Ovarian Cancer Patients: New Lessons From a Discovery Made 30 Years Ago
}

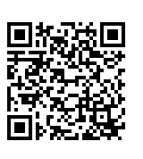

\author{
Jan Tesarik ${ }^{1,2 *}$, Raquel Mendoza-Tesarik ${ }^{1,2}$ and Carmen Mendoza ${ }^{1,2}$ \\ ${ }^{1}$ MARGen Clinic, Spain \\ ${ }^{2}$ MARGen Mendoza-Tesarik Foundation, Spain
}

Submission: May 28, 2018; Published: June 13, 2018

"Corresponding author: Jan Tesarik, MARGen Clinic, Camino de Ronda 2, 18006 Granada, Spain, Email: jtesarik@clinicamargen.com

\begin{abstract}
Patients whose ovaries are removed because of cancer or cancer menace may have pieces of the ovarian cortex cryopreserved for later autotransplantation. However, the autotransplantation is not possible in many cases, because of the risk of cancer recurrence. invitro growth and maturation of oocytes from primordial follicles of the cryopreseved ovarian cortex is a possible solution to this problem. This strategy works well in the mouse model. However, it fails to generate developmentally competent oocytes in the human species. This difference appears to be due to the relatively late onset of embryonic gene expression in humans, first demonstrated 30 years ago. Accordingly, developmentally competent human oocytes need to accumulate relatively high amounts of maternally derived messenger RNA, and probably other regulatory factors, to guide developmental events in the early postfertilization stages until the embryonic gene activation. The recent discovery of a particular mouse subspecies, whose embryos show a timing pattern of gene activity similar to that of human embryos, may facilitate future research in this field.
\end{abstract}

Keywords: Fertility preservation; Ovarian cancer; BRCA1 and BRCA2 mutations; Prophylactic oophorectomy; invitro follicle growth; Oocyte cytoplasmic maturation; Stored maternal mRNA; Embryonic gene activation; Spiny mouse model

\section{The Place of invitro Follicle Growth and Maturation in Fertility Preservation of Ovarian Cancer Patients}

Most ovarian cancer is diagnosed in women of non reproductive age, but the percentage of young women who survive ovarian cancer has increased as a result of improvements in diagnosis and earlier treatment [1]. These women are natural candidates for fertility preservation. If unilateral or bilateral salpingo-oophorectomy has to be accompanied by hysterectomy, the usefulness of fertility preservation techniques will depend on the possibility of surrogate motherhood. However, the uterus can be saved in some patients with existing ovarian cancer and, in particular, in those in whom oophorectomy is performed as a prophylactic intervention, such as in healthy carriers of a BRCA1 or BRCA2 mutations [2]. Cryopreservation of mature oocytes appears to be the first-choice treatment in these cases. However, controlled ovarian hyperstimulation, required for achieving the optimal quality and quantity of oocytes to be cryopreserved, can delay cancer treatment, may stimulate the rapid prolif $\neg$ eration of hormone-dependent cancer cells and is not possible in prepubertal girls [1]. Consequently, in vitro ovarian follicle growth and maturation remains the only possibility in some clinical scenarios. invitro Ovarian Follicle Growth and Maturation: The State of the Art

Methods for invitro growth and maturation of primordial ovarian follicles have been attempted in different mammalian species, but the birth of live off spring after in vitro fertilization of the resulting oocytes has only ever been achieved in mice $[3,4]$. In spite of exhaustive efforts [5], these results failed to be reproduced in humans. Even though the development of oocytes originating from human unilaminar follicles up to the metaphase II stage was achieved by using a multi-step culture system, fertilization of these oocytes was not attempted [6]. Similarly, metaphase II oocytes were obtained, with the use of different culture systems, from primordial follicles of nonhuman primates and domestic ruminant species [7-9], but all failed to produce live off spring after invitro fertilization and embryo transfer.

Why Do the Methods Developed in Mice Fail in Humans?

The clue to this question may be related to the differences in the onset of embryonic gene activation between mice and 
humans, discovered 30 years ago. While the mouse embryonic genome begins to be expressed as early as the 2-cell stage [10], gene activation is delayed until between the 4-cell and the 8-cell stages in humans. This discovery was definitely confirmed 30 years ago [11,12], although it had already been suggested by previous autoradiographic studies on RNA synthesis in human embryos $[13,14]$. Interestingly, a similar delay in the embryonic gene activation, as compared with the mouse, is also characteristic of cow, sheep and pig embryos [15], other mammalian species in which the techniques for primordial follicle growth and maturation, developed in the mouse, do not work correctly.

The delayed onset of embryonic gene expression in human, cow, sheep and pig embryos, as compared with the mouse, means that a longer period of early embro development is controlled by maternally derived molecules stored in the oocyte cytoplasm, mainly messenger RNA (mRNA). Stored maternal mRNA is protected against degradation within the oocyte cytoplasm by polyadenylation (addition of multiple adenosine monophosphates to the RNA molecule), and changes in the degree of polyadenylation during embryo development also regulate the function of the respective RNA species [15]. After the onset of embryonic gene activity, maternally derived mRNA is being increasingly degraded. However, experiments with human embryos have shown that, in spite of its progressive loss, oocytecoded message continues to be involved, together with the new embryo-derived message, in relatively late developmental events, such as cell polarization, endocytotic activity and the formation of intercellular junctional structures [16]. In this way oocytecoded message may contribute to essential developmental events taking place even after embryonic gene activation, such as the differentiation of the first two embryonic cell lineagesthe inner cell mass and the trophectoderm [16]. Some of the key maternal proteins encoded by maternal mRNA have been determined, primarily using genetically modified mouse models, and shown to be implicated in various aspects of early embryonic development, including maternal mRNA degradation, epigenetic reprogramming, signal transduction, protein translation and initiation of embryonic genome activation [17].

In all species studied so far, invitro culture of ovarian cortex leads to an accelerated growth of primordial follicles as compared with the invivo timing [5]. In view of the above interspecies differences in the onset of embryonic gene expression, this acceleration may be of little importance in the mouse as compared to the human. In fact, synthesis of stored maternal mRNA in oocytes ceases relatively early in folliculogenesis, before the beginning of the antrum formation, and fully grown oocytes become transcriptionally inactive and only utilize transcripts previously synthesized and stored during earlier development [18]. Consequently, the acceleration of primordial follicle growth during invitro culture may not leave to the oocytes of the species with delayed embryonic gene activation enough time to synthesize and store all information necessary for the early embryonic development.

\section{Practical Implications and Future Prospects}

The lessons derived from the above studies on gene activity regulation during early human development suggest that common mice do not represent a good animal model for the development of invitro culture systems for invitro growth and maturation of human primordial follicles. Fortunately, a recent publication [19] has reported data showing that a particular mouse subspecies, the spiny mouse (Acomys cahirinus), shares basic features of embryonic gene activation with humans and may thus represent a closer model for the study of human ovarian cortex invitro culture. The spiny mouse model can be used to design adequate invitro culture systems for primordial follicles, allowing the synthesis of a sufficient stock of the key regulatory molecules, to be used in the early embryonic development, in the resulting oocytes. This will hopefully help resolve the current problems of fertility preservation by invitro culture of the ovarian cortex in ovarian cancer patients.

\section{References}

1. Kim SY, Lee JR (2016) Fertility preservation option in young women with ovarian cancer. Future Oncol 12(14): 1695-1698.

2. Rebbeck TR, Lynch HT, Neuhausen SL, Narod SA, Garber JE, et al. (2002) Prophylactic oophorectomy in carriers of BRCA1 or BRCA2 mutations. N Engl J Med 346(21): 1616-1622.

3. Eppig JJ, O’Brien MJ (1996) Development invitro of mouse oocytes from primordial follicles. Biol Reprod 54(1): 197-207.

4. O’Brien MJ, Pendola JK, Eppig JJ (2003) A revised protocol for invitro development of mouse oocytes from primordial follicles dramatically improves their developmental competence. Biol Reprod 68(5): 16821686.

5. Bertoldo MJ, Walters KA, Ledger WL, Gilchrist RB, Mermillod P, et al. (2018) invitro regulation of primordial follicle activation: challenges for fertility preservation strategies. Reprod Biomed Online 36(5): 491499.

6. McLaughlin M, Albertini DF, Wallace WHB, Anderson RA, Telfer EE, et al. (2018) Metaphase II oocytes from human unilaminar follicles grown in a multi-step culture system. Mol Hum Reprod 24(3): 135-142.

7. McLaughlin M, Telfer EE (2010) Oocyte development in bovine primordial follicles is promoted by activin and FSH within a two-step serum-free culture system. Reproduction 139(6): 971-978.

8. Smitz J, Dolmans MM, Donnez J, Fortune JE, Hovatta O, et al. (2010) Current achievements and future research directions in ovarian tissue culture, invitro follicle development and transplantation: implications for fertility preservation. Hum Reprod Update 16(4): 395-414.

9. Telfer EE, Zelinski MB (2013) Ovarian follicle culture: advances and challenges for human and nonhuman primates. Fertil Steril 99(6): 1523-1533.

10. Taylor KD, Pikó L (1987) Patterns of mRNA prevalence and expression of B1 and B2 transcripts in early mouse embryos. Development 101(4): 877-892.

11. Braude P, Bolton V, Moore S (1988) Human gene expression first occurs between the four and eight cell stages of preimplantation development. Nature 332(6163): 459-461. 
12. Tesarik J, Kopecny V, Plachot M, Mandelbaum J (1988) Early morphological signs of embryonic genome expression in human preimplantation development as revealed by quantitative electron microscopy. Dev Biol 128(1): 15-20.

13. Tesarik J, Kopecny V, Plachot M, Mandelbaum J (1986) Activation of nucleolar and extranucleolar RNA synthesis and changes in the ribosomal content of human embryos developing invitro. J Reprod Fertil 78(2): 463-470.

14. Tesarik J, Kopecny V, Plachot M, Mandelbaum J, Lage DC, et al. (1986) Nucleologenesis in the human embryo developing invitro: Ultrastructural and autoradioraphic analysis. Dev Biol 115(1): 193203.

15. Telford NA, Watson AJ, Schultz GA (1990) Transition from maternal to embryonic control in early mammalian development: A comparison of several species. Mol Reprod Dev 26(1): 90-100.
16. Tesarik J (1989) Involvement of oocyte-coded message in cell differentiation control of early human embryos. Development 105(2): 317-322.

17. Zhang K, Smith GW (2015) Maternal control of early embryogenesis in mammals. Reprod Fertil Dev 27(6): 880-896.

18. Jansova D, Tetkova A, Koncicka M, Kubelka M, Susor A, et al. (2018) Localization of RNA and translation in the mammalian oocyte and embryo. PLoS ONE 13(3): e0192544.

19. Mamrot J, Gardner DK, Temple-Smith P, Dickinson H (2018) Embryonic gene transcription in the spiny mouse (Acomys cahirinus): an investigation into the embryonic genome activation. Bio Rxiv preprint.

\section{Your next submission with Juniper Publishers will reach you the below assets}

